Article

\title{
On Neutrosophic Extended Triplet LA-hypergroups and Strong Pure LA-semihypergroups
}

\author{
Minghao $\mathrm{Hu}^{1}$, Florentin Smarandache ${ }^{2} \mathbb{D}$ and Xiaohong Zhang ${ }^{1, *}$ \\ 1 Department of Mathematics, Shaanxi University of Science \& Technology, Xi'an 710021, China; \\ huminghao@sust.edu.cn \\ 2 Department of Mathematics, University of New Mexico, 705 Gurley Avenue, Gallup, NM 87301, USA; \\ smarand@unm.edu \\ * Correspondence: zhangxiaohong@sust.edu.cn
}

Received: 6 December 2019; Accepted: 9 January 2020; Published: 14 January 2020

\begin{abstract}
We introduce the notions of neutrosophic extended triplet LA-semihypergroup, neutrosophic extended triplet LA-hypergroup, which can reflect some symmetry of hyperoperation and discuss the relationships among them and regular LA-semihypergroups, LA-hypergroups, regular LA-hypergroups. In particular, we introduce the notion of strong pure neutrosophic extended triplet LA-semihypergroup, get some special properties of it and prove the construction theorem about it under the condition of asymmetry. The examples in this paper are all from Python programs.
\end{abstract}

Keywords: LA-semihypergroup; LA-hypergroup; neutrosophic extended triplet LA-semihypergroup; neutrosophic extended triplet LA-hypergroup

\section{Introduction and Preliminaries}

Left almost semigroup (abbreviated as LA-semigroup, some researchers also call it Abel Grassmann's groupoid), a non-associative and noncommutative algebraic structure, was first proposed by Kazim and Naseeruddin in Reference [1]. Hyperstructure theory was first introduced by Marty in Reference [2]. In the following decades and nowadays, various hyperstructures are widely studied and applied [3-6]. In Reference [7], Hila and Dine extended the concept of LA-semigroup to LA-semihypergroup and investigated several properties of LA-semihypergroups. Since then, many researchers have been done a lot of studies in this field [8-13].

In recent years, as an application of idea of neutrosophic set, the new notion of neutrosophic triplet group (NTG) was firstly introduced by F. Smarandache and M. Ali in Reference [14]. Soon after, M. Gulistan, S. Nawaz and N. Hassan applied the idea of NTG to LA-semihypergroup, proposed the concept of NTG-LA-semihypergroup and got some interesting results in Reference [15]. Meanwhile, F. Smarandache extended the concept of NTG to neutrosophic triplet extended group (NETG) in Reference [16]. Later, some research articles in this field are published. F. Smarandache, X.H. Zhang, X.G. An and Q.Q. Hu investigated properties and structures of NETG in Reference [17]; T.G. Jaíyéolá and F. Smarandache obtained some conclusions on neutrosophic triplet groups and discussed their applications in Reference [18]; The new concept of NET-Abel-Gassmann's Groupoid was introduced and the relationships of NETGs and regular semigroups were studied in Reference [19]; X.H. Zhang and X.Y. Wu prove that the construction theorem of NETG in Reference [20]; The concept of generalized neutrosophic extended group were proposed by Y.C. Ma and the relationships of NETGs and generalized groups were studied in References [21,22]. In particular, the notions of NET-semihypergroup and NET-hypergroup were introduced by X.H. Zhang, F. Smarandache and Y.C. Ma and the decomposition theorem of PWC-NET-semihypergroup was proved in Reference [23]. For the study of some related algebraic systems, please refer to Reference [24-26]. 
In this study, we apply the concept of NETG to LA-semihypergroup and introduce the new notions of NET-LA-semihypergroup, NET-LA-hypergroup, SPNET-LA-semihypergroup; Further, we discuss their properties, relations and so forth.

First of all, recall some conclusions and definitions on LA-semihypergroups.

Definition 1. [7] We say that a mapping

$$
\circ: H \times H \rightarrow P^{*}(H)
$$

is a binary hyperoperation, if $H$ is a nonempty set, $P(H)$ is power set of $H$ and $P^{*}(H)=P(H) / \phi$.

Definition 2. [7] $(H, \circ)$ is a binary hypergroupoid, if $H$ is a nonempty set and $\mathrm{o}$ is a binary hyperoperation. In addition, we write

$$
X \circ Y=\underset{a \in X, b \in Y}{\cup}(a \circ b), X \circ a=X \circ\{a\}, a \circ Y=\{a\} \circ Y,
$$

where $a \in H, X \subseteq H, Y \subseteq H$ and $X \neq \phi, Y \neq \phi$.

Definition 3. [7] A binary hypergroupoid $(H, \circ)$ is an LA-semihypergroup, if

$$
(a \circ b) \circ c=(c \circ b) \circ a
$$

for all $a, b, c \in H$, that is

$$
\underset{s \in(a \circ b)}{\cup}(s \circ c)=\underset{t \in(c \circ b)}{\cup}(t \circ a) .
$$

By Equation (1), we know that every LA-semihypergroup $(H$, o) satisfies

$$
(a \circ b) \circ(c \circ d)=(a \circ c) \circ(b \circ d)
$$

for all $a, b, c, d \in H$.

Note that, the Equations (1) and (3) are all set equations. If we replace all the elements in the equations (1) and (3) with nonempty subsets of $H$, these equations still hold.

Definition 4. [7] $(T, \circ)$ is a sub LA-semihypergroup of $(H, \circ)$, if the following conditions hold:

(a) $T \subseteq H, T \neq \phi$;

(b) $m \circ n \subseteq T$ for all $m, n \in T$;

(c) $(H, \circ)$ is an LA-semihypergroup.

Definition 5. [8] Suppose $(H, O)$ is an LA-semihypergroup. An element $a \in H$ is regular if there is an element $t$ $\in H$ such that

$$
a \in a \circ t \circ a .
$$

Furthermore, $(H, O)$ is a regular $L A$-semihypergroup if each element of $H$ is regular.

Definition 6. [7] Suppose $(H, \circ)$ is an LA-semihypergroup. $(H, \circ)$ is an LA-hypergroup if it satisfies

$$
t \circ H=H \circ t=H
$$

for all $t \in H$.

Definition 7. [8] Suppose $(H, \circ)$ is an LA-semihypergroup. An element e $\in H$ is

(a) a left identity, if $a \in e \circ$ a for each $a \in H$;

(b) a right identity, if $a \in a \circ$ e for each $a \in H$; 
(c) an identity, if $a \in(e \circ a) \cap(a \circ e)$ for each $a \in H$;

(d) a pure left identity, if $a=e \circ$ a for each $a \in H$;

(e) a pure right identity, if $a=a \circ$ e for each $a \in H$;

(f) a pure identity, if $a=(e \circ a) \cap(a \circ e)$ for each $a \in H$;

(g) a scalar identity, if $a=e \circ a=a \circ$ e for each $a \in H$.

In addition, we say that $x \in H$ is an inverse of $a \in H$ if $x$ satisfies

$$
e \in(a \circ x) \cap(x \circ a)
$$

where $e$ is an identity of $(H, \circ)$.

Definition 8. $(H, \circ)$ is a regular LA-hypergroup, if it satisfies the following conditions:

(a) $(H, \circ)$ is an LA-hypergroup;

(b) There exists e $\in H$ such that e is identity of $(H, \circ)$;

(c) Every element $a \in H$ has at least one inverse.

Definition 9. [16] A nonempty set $M$ is said to be a neutrosophic extended triplet set if to any given $a \in M$, there are $s \in M$ and $t \in M$, in such a way that

$$
\begin{aligned}
& a \circ s=s \circ a=a \\
& a \circ t=t \circ a=s,
\end{aligned}
$$

where $\circ$ is a binary operation on $M, s$ is an extend neutral of ' $a$ ', $t$ is an opposite of ' $a$ ' about $s,(a, s, t)$ is a neutrosophic extend triplet.

Definition 10. $[14,16]$ A semihypergroup $(H, \circ)$ is said to be an NET-semihypergroup if to any given $a \in H$, there are $s \in H$ and $t \in H$, in such a way that

$$
\begin{aligned}
& a \in(s \circ a) \cap(a \circ s), \\
& s \in(t \circ a) \cap(a \circ t) .
\end{aligned}
$$

In addition, for a certain $a \in H$, we say that $(a, s, t)$ is a hyper-neutrosophic-triplet and use \{\}$_{\text {neut }(a)}$ for the set of all $s$ that satisfy Formula (6) and (7). For a certain $s \in\{\}_{\text {neut }(a)}$, we use \{\}$_{\text {anti }(a)_{s}}$ for the set of all $t$ that satisfy Formula (7).

\section{Neutrosophic Extended Triplet LA-Semihypergroups and Neutrosophic Extended Triplet}

\section{LA-Hypergroups}

Definition 11. An LA-semihypergroup $(L, *)$ is said to be

(a) a left neutrosophic extended triplet LA-semihypergroup (LNET-LA-semihypergroup) if to any given $a \in L$, there are $p \in L$ and $q \in L$, in such a way that

$$
\begin{aligned}
& a \in p * a \\
& p \in q * a .
\end{aligned}
$$

Furthermore, for a certain $a \in L, p, q$ and $(a, p, q)$ are called left neutral of $a$, left opposite of a and left hyper-neutrosophic-triplet respectively. \{\}$_{\text {lneut }(a)}$ is used to represent the set of all $p$ that satisfy Formula (8), (9) and for a certain $p \in\{\}_{\text {lneut }(a)},\{\}_{\text {lanti(a) }}$ is used to represent the set of all $q$ that satisfy Formula (9).

(b) a right neutrosophic extended triplet LA-semihypergroup (RNET-LA-semihypergroup), if to any given $a \in L$, there are $s \in L$ and $t \in L$, in such a way that 


$$
\begin{aligned}
& a \in a * s \\
& s \in a * t .
\end{aligned}
$$

Furthermore, for a certain $a \in H,(a, s, t)$ is called right-hyper-neutrosophic-triplet. \{\}$_{\text {rneut }(a)}$ is used to represent the set of all s that satisfy Formula (10), (11) and for a certain $s \in\{\}_{\text {rneut }(a),}\{\}_{\text {ranti }(a)_{s}}$ is used to represent the set of all $t$ that satisfy Formula (11).

(c) a neutrosophic extended triplet LA-semihypergroup (NET-LA-semihypergroup), if to any given a $\in$, there are $m \in L$ and $n \in L$, in such a way that

$$
\begin{aligned}
& a \in(m * a) \cap(a * m) \\
& m \in(n * a) \cap(a * n) .
\end{aligned}
$$

Furthermore, for a certain $a \in L,(a, m, n)$ is called a hyper-neutrosophic-triplet, \{\}$_{\text {neut }(a)}$ is used to represent the set of all $m$ that satisfy Formula (12), (13) and for a certain $m \in\{\}_{\text {neut }(a)},\{\}_{\text {anti }(a)}$ is used to represent the set of all $n$ that satisfy Formula (13).

Example 1. Put $L=\{0,1,2\}$, the binary hypergroupoid $(L, *)$ is as follows (see Table 1).

Table 1. The binary hypergroupoid $(L, *)$.

\begin{tabular}{cccc}
\hline$*$ & $\mathbf{0}$ & $\mathbf{1}$ & $\mathbf{2}$ \\
\hline $\mathbf{0}$ & 0 & 0 & 0 \\
$\mathbf{1}$ & 0 & 1 & 0 \\
$\mathbf{2}$ & 0 & 0 & $\{0,2\}$ \\
\hline
\end{tabular}

By Python program $1,(L, *)$ is an LA-semihypergroup (please see Figure 1).

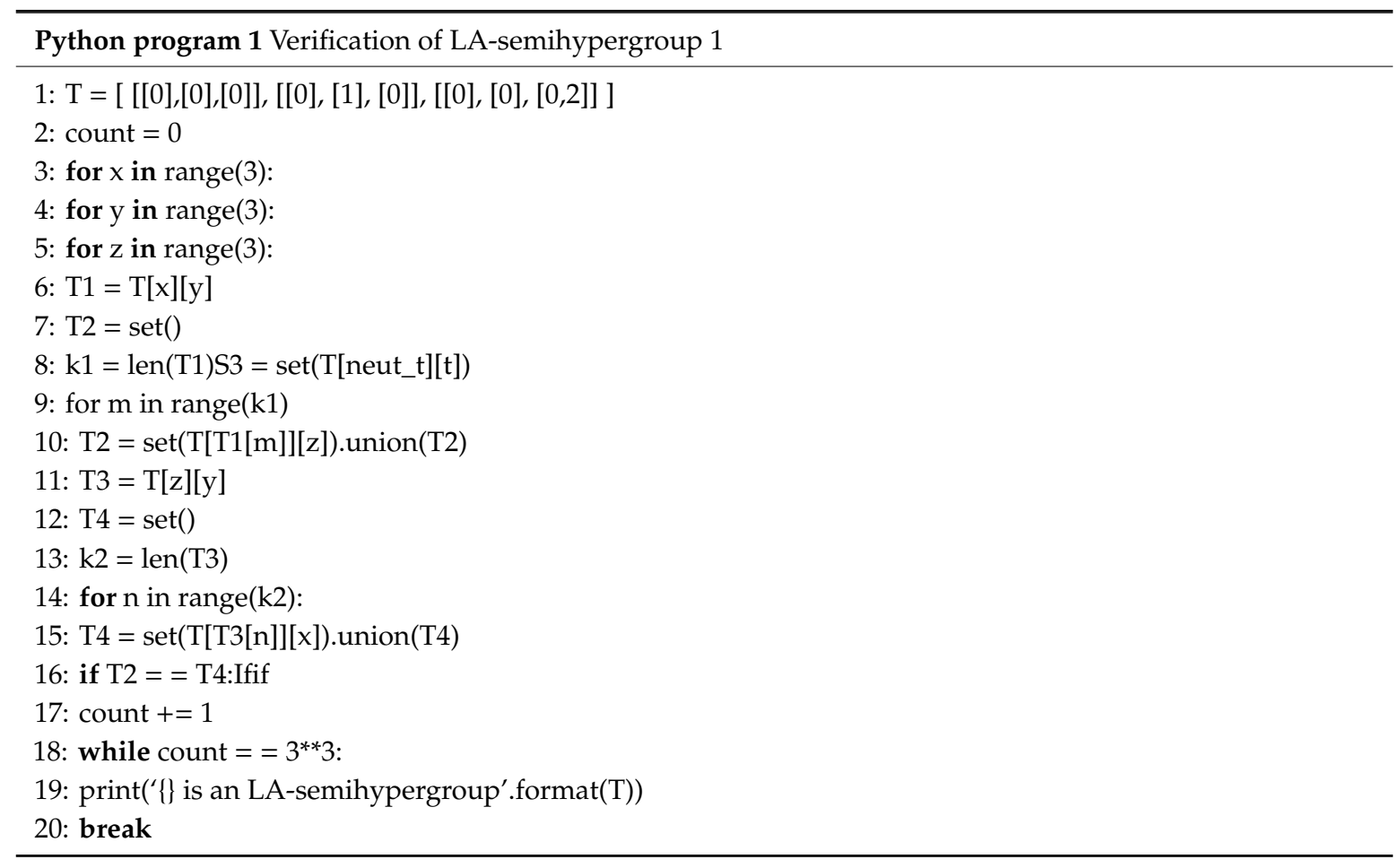




\section{Run: program 1}

$\mathrm{C}: \backslash$ Users $\backslash$ Think $\backslash$ Anaconda3 $\backslash$ python.exe C:/Users/Think/PycharmProjects/1/program1.py [ [[0],[0],[0]], [[0], [1], [0]], [[0], [0], [0,2]] ] is an LA-semihypergroup.

Process finished with exit code 0

Figure 1. The result of Python program 1.

Furthermore, we get

$$
\begin{aligned}
& 0 \in(0 * 0) \cap(0 * 0), 0 \in(0 * 0) \cap(0 * 0) \\
& 0 \in(0 * 0) \cap(0 * 0), 0 \in(1 * 0) \cap(0 * 1) \\
& 0 \in(0 * 0) \cap(0 * 0), 0 \in(2 * 0) \cap(0 * 2) \\
& 1 \in(1 * 1) \cap(1 * 1), 1 \in(1 * 1) \cap(1 * 1) \\
& 2 \in(2 * 2) \cap(2 * 2), 2 \in(2 * 2) \cap(2 * 2) .
\end{aligned}
$$

By Definition $11,(0,0,0),(0,0,1),(0,0,2)(1,1,1),(2,2,2)$ are all hyper neutrosophic-triplets and $(L, *)$ is an NET-LA-semihypergroup. These results can also be verified by Python program 2 (please see Figure 2).

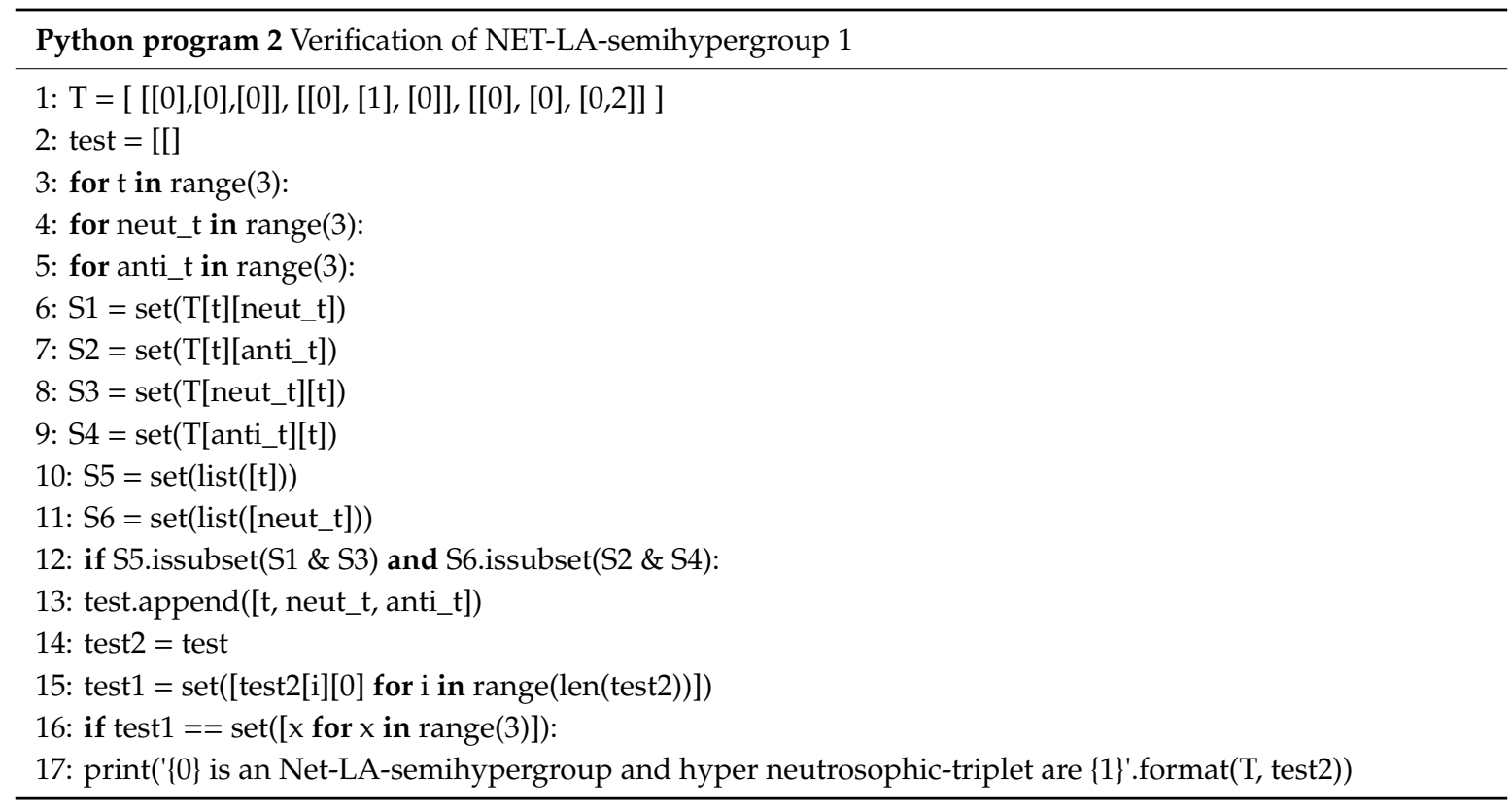

Run: programm 2

$\mathrm{C}: \backslash$ Users \Think \Anaconda3\python.exe C:/Users/Think/PycharmProjects/1/program2.py [ [[0],[0],[0]], [[0], [1], [0]], [[0], [0], [0,2]] ] is an Net-LA-semihypergroup and hyper neutrosophictriplet are [[0,0,0], [0,0,1], [0,0,2], [1,1,1], [2,2,2]]

Process finished with exit code 0

Figure 2. The result of Python program 2. 
Example 2. Suppose $R$ is the set of real numbers, the binary hypergroupoid $(R, *)$ is as follows.

$$
x * y= \begin{cases}(x, y) & x<y \\ (y, x) & y<x \\ x & x=y\end{cases}
$$

for all $x, y \in R$, where $(x, y)$ is the open interval.

When $z<x<y$,

$$
\begin{gathered}
(x * y) * z=\cup_{s \in(x * y)}(s * z) \underset{s \in(x, y)}{\cup}(z, s)=(z, y) \\
(z * y) * x=\cup_{t \in(z * y)}(t * x)=\bigcup_{t \in(z, y)}(t * x)=\left[\cup_{t \in(z, x)}^{\cup}(t * x)\right] \cup\left[\cup_{t=x}(t * x)\right] \cup[\underset{t \in(x, y)}{\cup}(t * x)] \\
=\left[\bigcup_{t \in(z, x)}(t, x)\right] \cup(\{x\}) \cup[\underset{t \in(x, y)}{\cup}(x, t)]=(z, x) \cup(\{x\}) \cup(x, y)=(z, y)=(x * y) * z .
\end{gathered}
$$

In the same way, we have

$$
(x * y) * z=(z * y) * x,
$$

for all $x, y, z \in R$. Hence $(R, *)$ is an LA-semihypergroup. On the other hand, Since

$$
x \in(x * x) \cap(x * x), x \in(x * x) \cap(x * x),
$$

for any given $x \in R, x \in\{\}_{\text {neut }(x)}, x \in\{\}_{\text {anti }(x)_{x}}$. By Definition $11,(R, *)$ is an NET-LA-semihypergroup.

Example 3. Put $L=\{0,1,2\}$, the binary hypergroupoid $(L, *)$ is as follows (see Table 2).

Table 2. The binary hypergroupoid $(L, *)$.

\begin{tabular}{cccc}
\hline$*$ & $\mathbf{0}$ & $\mathbf{1}$ & $\mathbf{2}$ \\
\hline 0 & 0 & 0 & 0 \\
1 & 0 & 0 & 0 \\
2 & 0 & 0 & $\{0,1\}$ \\
\hline
\end{tabular}

By Python program, $(L, *)$ is an LA-semihypergroup. In addition, we get

$$
1 \notin(0 * 1) \cap(1 * 0), 1 \notin(1 * 1) \cap(1 * 1), 1 \notin(2 * 1) \cap(1 * 2) .
$$

This shows that \{\}$_{\text {neut }(1)}=\phi$. By Definition $11,(L, *)$ is not an NET-LA-semihypergroup.

Remark 1. Every NET-LA-semihypergroup is an LA-semihypergroup but not vice versa.

Example 4. Put $L=\{0,1,2,3\}$, the binary hypergroupoid $(L, *)$ is as follows (see Table 3 ).

Table 3. The binary hypergroupoid $(L, *)$.

\begin{tabular}{ccccc}
\hline$*$ & $\mathbf{0}$ & $\mathbf{1}$ & $\mathbf{2}$ & $\mathbf{3}$ \\
\hline $\mathbf{0}$ & 0 & 0 & 0 & $\{0,1,2,3\}$ \\
$\mathbf{1}$ & 0 & 0 & 0 & $\{0,1,2,3\}$ \\
$\mathbf{2}$ & 0 & 0 & $\{0,1\}$ & $\{2,3\}$ \\
$\mathbf{3}$ & $\{1,2,3\}$ & $\{0,1,2,3\}$ & $\{2,3\}$ & $\{0,3\}$ \\
\hline
\end{tabular}

By Python program 3 and Python program $4,(L, *)$ is both an LA-semihypergroup (please see Figure 3$)$ and an NET-LA-semihypergroup (please see Figure 4). In addition,

$$
(0,0,0),(0,0,1),(0,0,2),(0,1,3),(0,2,3),(1,3,3),(2,3,3)
$$


$(3,0,1),(3,0,3),(3,1,0),(3,1,1),(3,2,0),(3,2,1),(3,2,2),(3,3,0),(3,3,1),(3,3,2),(3,3,3)$ are all hyper neutrosophic-triplets(please see Figure 4 ). Let $M=\{0,1,2\} \subseteq L$, then $(M, *)$ is a sub LA-semihypergroup of $(L, *)$. From Example $3,(M, *)$ is not an NET-LA-semihypergroup.

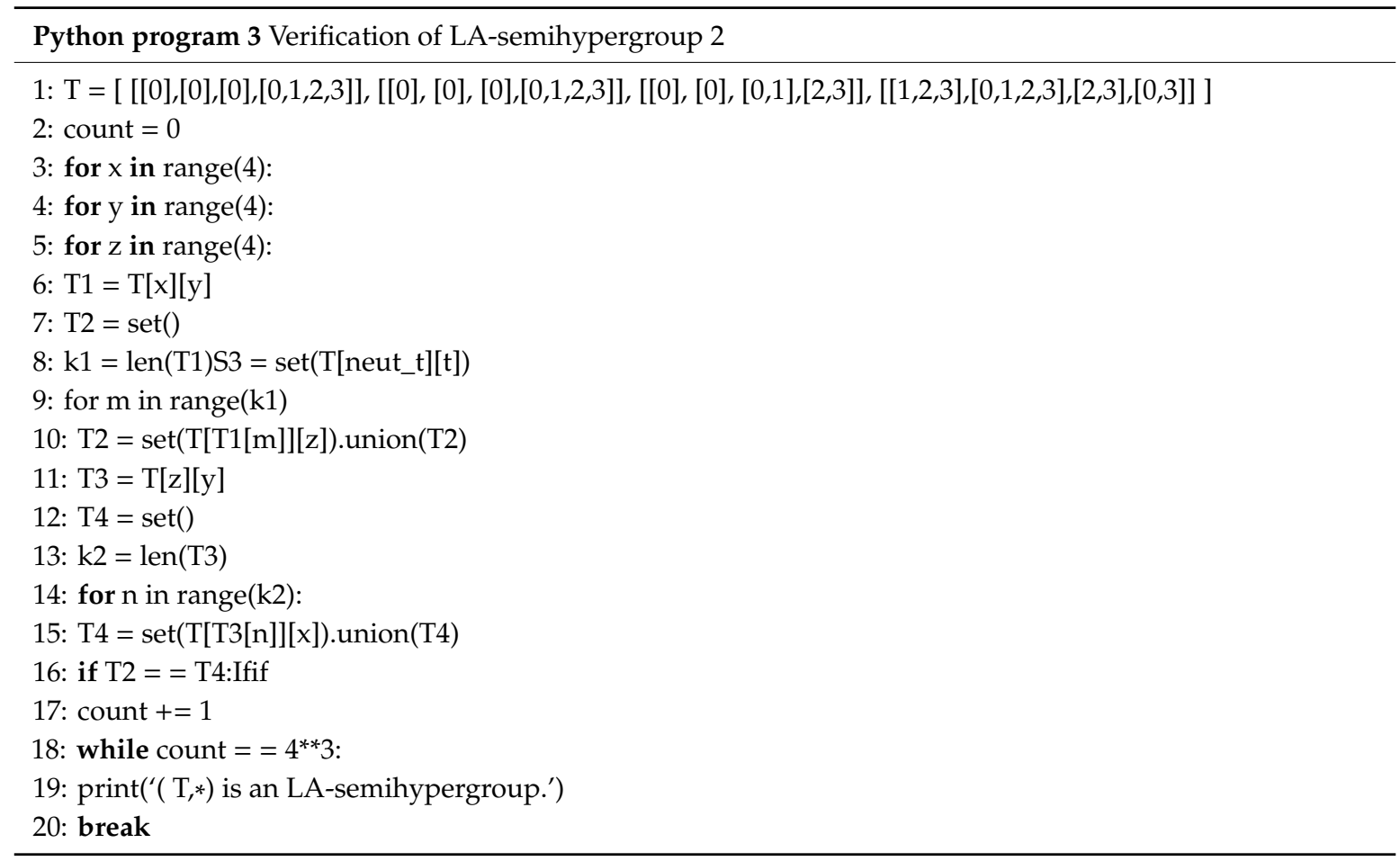

\section{Run: program 3}

C:\Users \Think \Anaconda3\python.exe C:/Users/Think/PycharmProjects/1/program3.py

$(\mathrm{T}, *)$ is an LA-semihypergroup.

Process finished with exit code 0

Figure 3. The result of Python program 3.

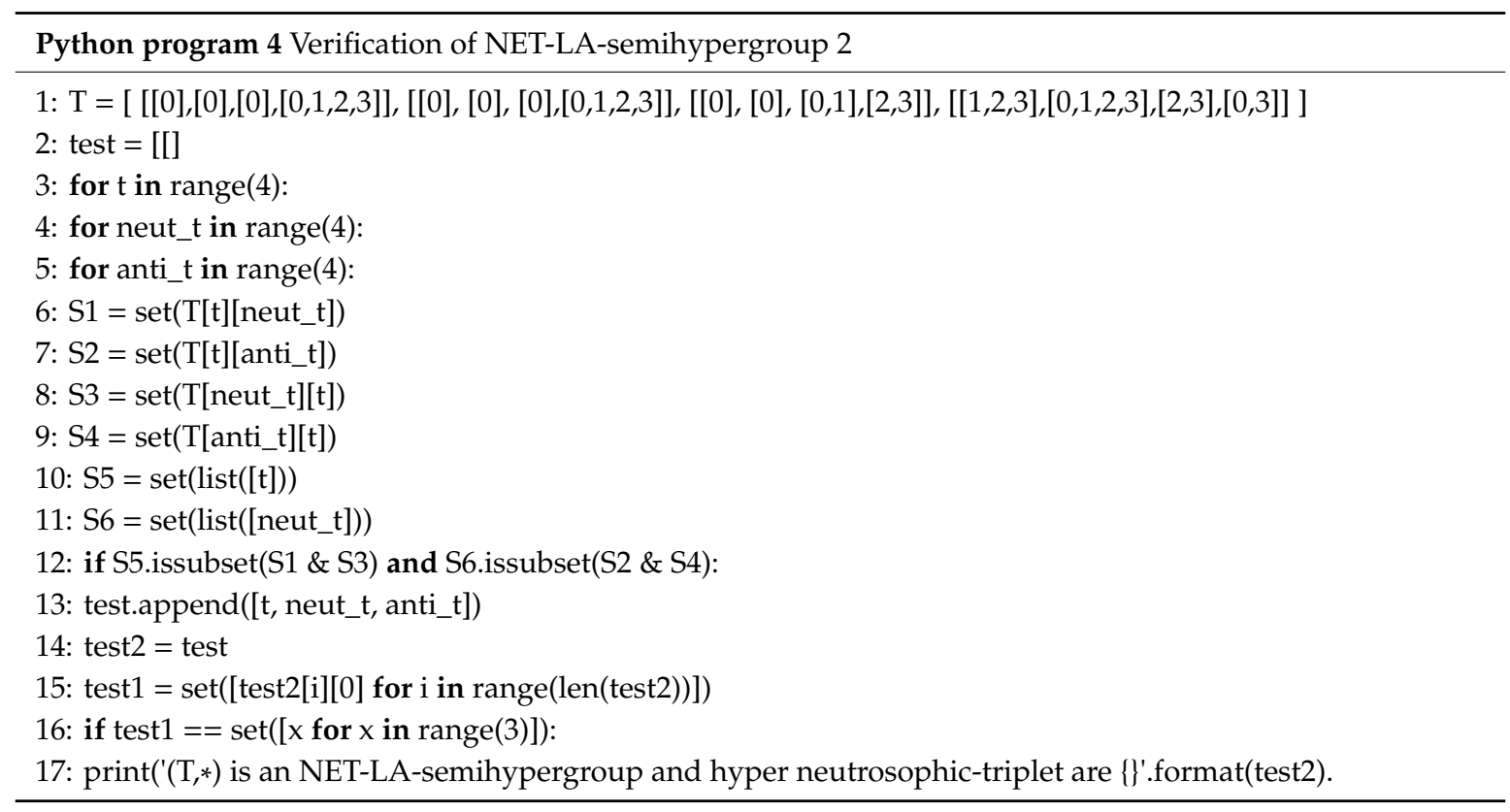




\section{Run: program 4}

$\mathrm{C}: \backslash$ Users $\backslash$ Think $\backslash$ Anaconda $3 \backslash$ python.exe C:/Users/Think/PycharmProjects/1/proram4.py

$(\mathrm{T}, *)$ is an NET-LA-semihypergroup and hyper neutrosopic-triplet are [[0,0,0], [0,0,1], [0,0,2],

$[0,2,3],[1,3,3],[2,3,3],[3,0,1],[3,0,3],[3,1,0], \quad[3,1,1], \quad[3,2,0], \quad[3,2,1], \quad[3,2,2],[3,3,0],[3,3,1]$,

[3,3,2], [3,3,3]]

Process finished with exit code 0

Figure 4. The result of Python program 4.

Remark 2. From Example 4, we know that for a certain $t$ in an NET-LA-semihypergroup, $\left|\{\}_{\text {neut }(x)}\right|$ may be greater than or equal to one and for a certain $p \in\{\}_{\text {neut }(x)},\left|\{\}_{\text {anti }(x)}\right|$ may be greater than or equal to one. According to the results of Example 4, we have

$$
\begin{gathered}
\{\}_{\text {neut }(0)}=\{0,1,2\},\{\}_{\text {anti }(0)_{0}}=\{0,1,2\},\{\}_{\text {anti }(0)_{1}}=\{3\},\{\}_{\text {anti }(0)_{2}}=\{3\} \\
\{\}_{\text {neut }(1)}=\{3\},\{\}_{\text {anti }(1)_{3}}=\{3\} ;\{\}_{\text {neut }(2)}=\{3\},\{\}_{\text {anti }(2)_{3}}=\{3\} \\
\{\}_{\text {neut }(3)}=\{0,1,2,3\},\{\}_{\text {anti }(3)_{0}}=\{3\},\{\}_{\text {anti }(3)_{1}}=\{0,1\},\{\}_{\text {anti }(3)_{2}}=\{0,1,2\} ;\{\}_{\text {anti }(3)_{3}}=\{0,1,2,3\}
\end{gathered}
$$

Definition 12. ( $L, *)$ is said to be an NET-LA-hypergroup if it is both an LA-hypergroup (see Definition 6) and an NET-LA-semihypergroup.

Proposition 1. Every LA-hypergroup is a regular LA-semihypergroup.

Proof. Since $(L, *)$ is an LA-hypergroup, to every $t \in L, t * L=L * t=L$. Thus

$$
t \in L=L * t=t * L * t
$$

By Definition 5, $(L, *)$ is a regular LA-semihypergroup.

Example 5. Put $L=\{0,1,2\}$, the binary hypergroupoid ( $L, *)$ is as follows (see Table 4).

Table 4 . The binary hypergroupoid $(L, *)$.

\begin{tabular}{cccc}
\hline$*$ & $\mathbf{0}$ & $\mathbf{1}$ & $\mathbf{2}$ \\
\hline $\boldsymbol{0}$ & 0 & 0 & 0 \\
$\mathbf{1}$ & 0 & 1 & $\{0,1\}$ \\
$\mathbf{2}$ & 0 & $\{0,1\}$ & $\{2\}$ \\
\hline
\end{tabular}

By Python program, $(L, *)$ is an LA-semihypergroup. Furthermore, we have

$$
0 \in 0 * 0 * 0,1 \in 1 * 2 * 1,2 \in 2 * 2 * 2
$$

By Definition $5,(L, *)$ is a regular LA-semihypergroup. But

$$
0 * L=0 \neq L
$$

By Definition 6, $(L, *)$ is not an LA-hypergroup.

Remark 3. From Example 5, a regular LA-semihypergroup is not necessarily an LA-hypergroup.

Proposition 2. Every NET-LA-semihypergroup is a regular LA-semihypergroup. 
Proof. Suppose $(L, *)$ is an NET-LA-semihypergroup, then to any given $a \in L$, there are $p \in\{\}_{\text {neut }(a)} \subseteq L$ and $q \in\{\}_{\text {anti }(a)_{p}} \subseteq L$ such that

$$
\begin{aligned}
& a \in(p * a) \cap(a * p) \\
& p \in(q * a) \cap(a * q)
\end{aligned}
$$

Hence

$$
a \in(p * a) \text { and } p \in(a * q)
$$

that is

$$
a \in p * a \in(a * q) * a
$$

By Definition $5,(\mathrm{~L}, *)$ is a regular LA-semihypergroup.

Example 6. Put $L=\{0,1,2\}$, the binary hypergroupoid $(L, *)$ is as follows (see Table 5).

Table 5. The binary hypergroupoid $(L, *)$.

\begin{tabular}{cccc}
\hline$*$ & $\mathbf{0}$ & $\mathbf{1}$ & $\mathbf{2}$ \\
\hline 0 & 0 & 0 & 0 \\
1 & 0 & 2 & 2 \\
2 & 0 & $\{0,1,2\}$ & $\{0,1,2\}$ \\
\hline
\end{tabular}

By Python program, $(L, *)$ is an LA-semihypergroup. Furthermore, we have

$$
0 \in 0 * 0 * 0,1 \in 1 * 2 * 1,2 \in 2 * 1 * 2
$$

By Definition $5,(L, *)$ is a regular LA-semihypergroup. But

$$
1 \notin(0 * 1) \cap(1 * 0), 1 \notin(1 * 1) \cap(1 * 1), 1 \notin(2 * 1) \cap(1 * 2)
$$

This shows that \{\}$_{\text {neut }(1)}=\phi$. By Definition $11,(L, *)$ is not an NET-LA-semihypergroup.

Remark 4. From Example 6, a regular LA-semihypergroup is not necessarily an NET-LA-semihypergroup.

Example 7. Put $L=\{0,1,2\}$, the binary hypergroupoid $(L, *)$ is as follows (see Table 6).

Table 6. The binary hypergroupoid $(L, *)$.

\begin{tabular}{cccc}
\hline$*$ & $\mathbf{0}$ & $\mathbf{1}$ & $\mathbf{2}$ \\
\hline 0 & 0 & 0 & 0 \\
1 & 0 & 1 & 0 \\
2 & 0 & 0 & $\{0,2\}$ \\
\hline
\end{tabular}

By Python program, $(L, *)$ is an LA-semihypergroup. Furthermore, we get

$$
(0,0,0),(0,0,1),(0,0,2),(1,1,1),(2,2,2)
$$

are all hyper neuromorphic-triplets. By Definition $11,(L, *)$ is an NET-LA-semihypergroup. But

$$
0 * L=0 \neq L
$$

By Definition 6, $(L, *)$ is not an LA-hypergroup. 
Example 8. Put $L=\{0,1,2\}$, the binary hypergroupoid ( $L, *)$ is as follows (see Table 7 ).

Table 7. The binary hypergroupoid $(L, *)$.

\begin{tabular}{cccc}
\hline$*$ & $\mathbf{0}$ & $\mathbf{1}$ & $\mathbf{2}$ \\
\hline 0 & 0 & $\{0,1,2\}$ & $\{0,1,2\}$ \\
1 & 0 & $\{0,2\}$ & $\{1,2\}$ \\
2 & $\{0,1,2\}$ & $\{0,2\}$ & $\{0,1,2\}$ \\
\hline
\end{tabular}

By Python program, $(L, *)$ is an LA-semi hypergroup. Furthermore, we get

$$
0 * L=L * 0=L, 1 * L=L * 1=L, 2 * L=L * 2=L
$$

By Definition 6, $(L, *)$ is an LA-hypergroup. But

$$
1 \notin(0 * 1) \cap(1 * 0), 1 \notin(1 * 1) \cap(1 * 1), 1 \notin(2 * 1) \cap(1 * 2)
$$

This shows that \{\}$_{\text {neut }(1)}=\phi$. By Definition $11,(L, *)$ is not an NET-LA-semihypergroup.

Proposition 3. Every regular LA-hypergroup is an NET-LA-hypergroup.

Example 9. Put $L=\{0,1,2\}$, the binary hypergroupoid ( $L, *)$ is as follows (see Table 8).

Table 8. The binary hypergroupoid $(L, *)$.

\begin{tabular}{cccc}
\hline$*$ & $\mathbf{0}$ & $\mathbf{1}$ & $\mathbf{2}$ \\
\hline 0 & $\{1,2\}$ & $\{0,1,2\}$ & $\{0,1,2\}$ \\
1 & $\{0,1,2\}$ & $\{0,2\}$ & $\{0,2\}$ \\
2 & $\{0,1\}$ & $\{1,2\}$ & $\{0,1\}$ \\
\hline
\end{tabular}

By Python program, $(L, *)$ is an LA-semihypergroup. Furthermore, we get

$$
(0,1,0),(0,1,1),(0,1,2),(0,2,0),(0,2,1),(1,0,0),(1,0,1),(2,1,0),(2,1,2)
$$

are all hyper neutrosophic-triplets, and

$$
0 * L=L * 0=L, 1 * L=L * 1=L, 2 * L=L * 2=L
$$

by Definition $12,(L, *)$ is an NET-LA-hypergroup. But

$$
0 \notin(0 * 0) \cap(0 * 0), 1 \notin(1 * 1) \cap(1 * 1), 2 \notin(2 * 2) \cap(2 * 2)
$$

This shows that the identity of $(L, *)$ does not exist. By Definition $8,(L, *)$ is not a regular LA-hypergroup.

Based on the above, the relationships of LA-semihypergroup, regular LA-semihypergroup, LA-hypergroup, NET-LA-semihypergroup, NET-LA-hypergroup and regular LA-hypergroup, can be represented by the flowing Figure 5 . 


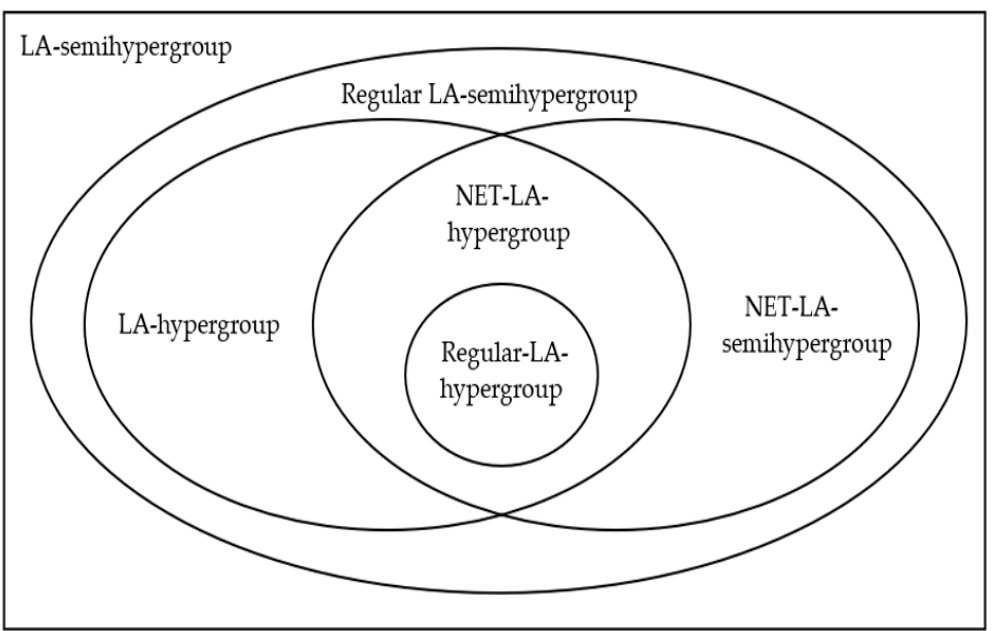

Figure 5. The relationships of various LA-semihypergroups.

Proposition 4. An NET-LA-semihypergroup (L, *) is both an LNET-LA-semihypergroup and a RNET-LA-semihypergroup.

Proof. Since $(L, *)$ is an NET-LA-semihypergroup, to any given a $\in \mathrm{L}$, there are $s \in\{\}_{\text {neut }(a)}$ and $t \in\{\}_{\text {anti }(a)_{s}}$ such that

$$
a \in(s * a) \cap(a * s) \text { and } s \in(t * a) \cap(a * t) \text {. }
$$

Hence $a \in(s * a)$ and $s \in(t * a)$, This shows

$$
s \in\{\}_{\text {lneut }(a)} \in\{\}_{\text {lanti }(a)_{s}} .
$$

Thus $(L, *)$ is an LNET-LA-semihypergroup. In the same way, we can prove that $(L, *)$ is also a RNET-LA-semihypergroup.

Example 10. Put $L=\{0,1,2\}$, the binary hypergroupoid $(L, *)$ is as follows (see Table 9).

Table 9. The binary hypergroupoid $(L, *)$.

\begin{tabular}{cccc}
\hline$*$ & $\mathbf{0}$ & $\mathbf{1}$ & $\mathbf{2}$ \\
\hline 0 & 0 & 0 & 0 \\
1 & 0 & 2 & 2 \\
2 & 0 & $\{1,2\}$ & $\{1,2\}$ \\
\hline
\end{tabular}

By Python program, $(L, *)$ is an LA-semihypergroup a nd

$$
(0,0,0),(0,0,1),(0,0,2),(1,2,1),(1,2,2),(2,1,2),(2,2,1),(2,2,2)
$$

are all left-hyper neutrosophic-triplets;

$$
(0,0,0),(0,0,1),(0,0,2),(2,1,1),(2,1,2),(2,2,1),(2,2,2)
$$

are all right-hyper neutrosophic-triplets;

$$
(0,0,0),(0,0,1),(0,0,2),(2,1,2),(2,2,1),(2,2,2)
$$

are all hyper neutrosophic-triplets. By Definition $11,(L, *)$ is an LNET-LA-semihypergroup but it is neither a RNET-LA-semihypergroup nor an NET-LA-semihypergroup. 
Example 11. Put $L=\{0,1,2\}$, the binary hypergroupoid $(L, *)$ is as follows (see Table 10).

Table 10. The binary hypergroupoid $(L, *)$.

\begin{tabular}{cccc}
\hline$*$ & 0 & 1 & $\mathbf{2}$ \\
\hline 0 & 0 & $\{0,1,2\}$ & $\{0,1,2\}$ \\
1 & 2 & 2 & $\{1,2\}$ \\
2 & $\{0,1,2\}$ & $\{0,2\}$ & $\{0,1,2\}$ \\
\hline
\end{tabular}

By Python program, $(L, *)$ is an LA-semihypergroup and

$$
\begin{aligned}
& (0,0,0),(0,0,2),(0,2,1),(0,2,2),(1,0,0),(1,0,2),(2,0,0) \\
& (2,0,2),(2,1,0),(2,1,1),(2,1,2),(2,2,0),(2,2,1),(2,2,2)
\end{aligned}
$$

are all left-hyper neutrosophic-triplets;

$$
(0,0,0),(0,0,1)(0,0,2),(0,1,1),(0,1,2)(0,2,1),(0,2,2),(1,2,0),(1,2,1)
$$

$$
(1,2,2),(2,0,0),(2,0,1),(2,0,2),(2,1,0),(2,1,2),(2,2,0),(2,2,1),(2,2,2)
$$

are all right-hyper neutrosophic-triplets; But

$$
1 \notin(0 * 1) \cap(1 * 0), 1 \notin(1 * 1) \cap(1 * 1), 1 \notin(2 * 1) \cap(1 * 2)
$$

This shows that \{\}$_{\text {neut }(1)}=\phi$. By Definition $11,(L, *)$ is both an LNET-LA-semihypergroup and a RNET-LA-semihypergroup but not an NET-LA-semihypergroup. Moreover, from Example 11, we know that

$$
\begin{gathered}
\{\}_{\text {lneut }(0)}=\{0,2\},\{\}_{\text {lanti }(0)_{0}}=\{0,2\},\{\}_{\text {lanti }(0)_{2}}=\{1,2\} \\
\{\}_{\text {lneut }(1)}=\{0\},\{\}_{\text {lanti }(1)_{0}}=\{0,2\} \\
\{\}_{\text {lneut }(2)}=\{0,1,2\},\{\}_{\text {lanti }(2)_{0}}=\{0,2\},\{\}_{\text {lanti }(2)_{1}}=\{0,1,2\},\{\}_{\text {lanti }(2)_{2}}=\{0,1,2\}
\end{gathered}
$$

These means that for a certain $x$ in an LNET-LA-semihypergroup, $\left|\{\}_{\text {lneut }(x)}\right|$ may be greater than or equal to one and for a certain $p \in\{\}_{\text {heut }(x)},\left|\{\}_{\text {lanti }(x)_{p}}\right|$ may be greater than or equal to one. There are similar conclusions in RNET-LA-semihypergroup. In addition, for a certain $x$ in an LA-semihypergroup, if $s \in\{\}_{\text {lneut }(x)}$ (or $s \in$ \{\}$\left._{\text {rneut }(x)}\right)$, then s may be not in \{\}$_{\text {rneut }(x)}\left(\right.$ or \{\}$\left._{\text {lneut }(x)}\right)$. By Example 11 , we have $1 \in\{\}_{\text {rneut }(0)}$ but $1 \notin\{\}_{\text {lneut }(0)}$.

Remark 5. Non-LNET-LA-semihypergroup (or Non-RNET-LA-semihypergruop) is not an NET-LA-semihypergroup. $(L, *)$ is both an LNET-LA-semihypergroup and a RNET-LA-semihypergroup but it is not necessarily an NET-LA-semihypergroup.

Based on the above, the relationships of NET-LA-semihypergroup, RNET-LA-semihypergroup and LNET-LA-hypergroup, can be represented by Figure 6. 


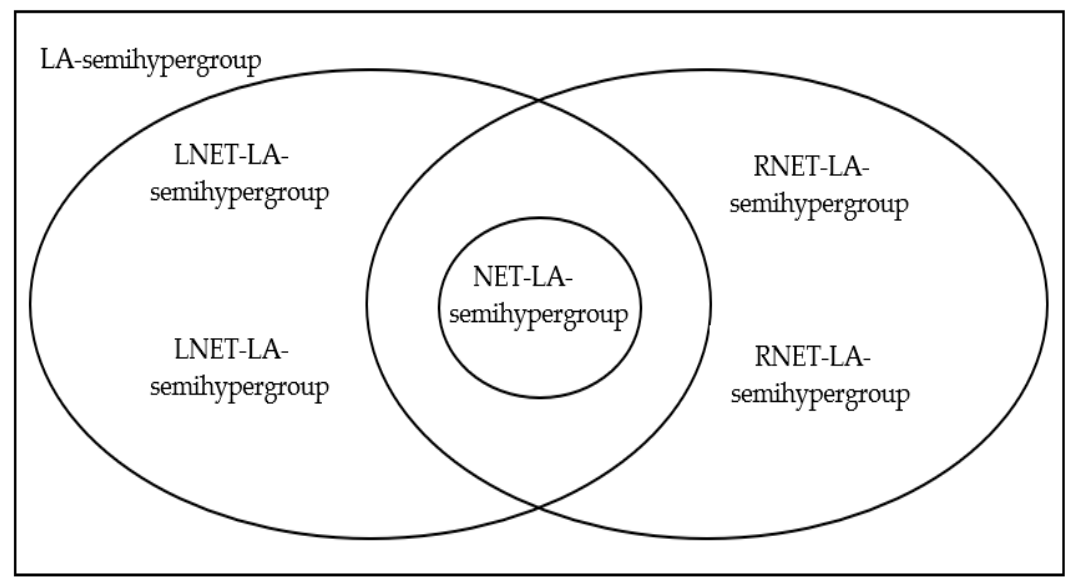

Figure 6. The relationships of various LA-semihypergroups.

\section{Strong Pure Neutrosophic Extended Triplet LA-Semihypergroups (SPNET-LA-Semihypergroups)}

Definition 13. An LA-semihypergroup $(L, *)$ is said to be

(a) a pure left neutrosophic extended triplet LA-semihypergroup (PLNET-LA-semihypergroup), if to any given $a \in L$, there are $p \in L$ and $q \in L$, in such a way that

$$
a=p * a \text { and } p=q * a
$$

(b) a pure right neutrosophic extended triplet LA-semihypergroup (PRNET-LA-semihypergroup), if to any given $a \in L$, there are $s \in L$ and $t \in L$, in such a way that

$$
a=a * s \text { and } s=a * t
$$

(c) a pure neutrosophic extended triplet LA-semihypergroup (PNET-LA-semihypergroup), if to any given a $\in$ $L$, there are $m \in L$ and $n \in L$, in such a way that

$$
a=(m * a) \cap(a * m) \text { and } m=(n * a) \cap(a * n)
$$

(d) a strong pure neutrosophic extended triplet LA-semihypergroup (SPNET-LA-semihypergroup), if to any given $a \in L$, there are $m \in L$ and $n \in L$, in such a way that

$$
a=m * a=a * m \text { and } m=n * a=a * n
$$

Proposition 5. Every SPNET-LA-semihypergroup is a PNET-LA-semihypergroup; Every PNET-LA-semihypergroup is an NET-LA-semihypergroup. Every PLNET-LA-semihypergroup is an LNET-LA-semihypergroup; Every PRNET-LA-semihypergroup is a RNET-LA-semihypergroup.

Remark 6. From Proposition 5, we know that the signs in the Definition 11 can still be used, such as \{\}$_{\text {lneut }(a) \text {, }}$ \{\}$_{\text {rneut }(a)},\{\}_{\text {neut }(a)},\{\}_{\text {lanti }(a)_{p},}\{\}_{\text {ranti }(a)_{p},}$ etc.

Proposition 6. Every commutative PNET-LA-semihypergroup is an SPNET-LA-semihypergroup; Every commutative PLNET-LA-semihypergroup(or PRNET-LA-semihypergroup) is an SPNET-LA-semihypergroup.

Proposition 7. Suppose $(L, *)$ is an SPNET-LA-semihypergroup, for any $a, b, c \in L$,

(1) if $s \in\{\}_{\text {neut }(a)}$, then $\mathrm{s}$ is unique and $\mathrm{s} * \mathrm{~s}=\mathrm{s}$;

(2) if $s=\operatorname{neut}(a)$, then neut $(s)=s$ and $s \in\{\}_{\text {anti( }(s)}$; 
(3) if $s=n e u t(a), t \in\{\}_{\text {anti }(a)_{s}}, r \in\{\}_{\text {anti }(s)_{s}}$, then $r * t \subseteq\{\}_{\text {lanti }(a)_{s}}$;

(4) if $s=\operatorname{neut}(a), t \in\{\}_{\text {anti }(a)_{s}}$, then $s * t \subseteq\{\}_{\text {lanti }(a)_{s}}$;

(5) if $p=\operatorname{neut}(a), s=\operatorname{neut}(b), q \in\{\}_{\text {anti }(a)_{p}, t}, \in\{\}_{\text {anti }(b)_{s}}$ and $|a * b|=|p * s|=1$, then

$$
\operatorname{neut}(a * b)=p * \operatorname{sandq} * t \subseteq\{\}_{\text {anti }(a * b)_{p * s}}
$$

(6) if $s=\operatorname{neut}(a)=\operatorname{neut}(b), q \in\{\}_{\text {anti }(a)_{s}}, t \in\{\}_{\text {anti }(b)_{s}}$ and $|a * b|=1$, then

$$
\operatorname{neut}(a * b)=\operatorname{sandq} * t \subseteq\{\}_{a n t i(a * b)_{s}}
$$

(7) if neut $(a)=\operatorname{neut}(b)$, then $a * b=b * a$;

(8) then $s * b=s * c$ if $b * a=c * a$, where $s=n e u t(a)$;

(9) if $s=\operatorname{neut}(a), q, t \in\{\}_{\text {anti }(a)_{s}}$, then $\mathrm{s} * \mathrm{q}=\mathrm{s} * \mathrm{t}$.

Proof. (1) Suppose there are $s, p \in\{\}_{\text {neut }(a)}, t \in\{\}_{\text {anti }(a)_{s^{\prime}}}, q \in\{\}_{\text {anti }(a))_{p}} \cdot(L, *)$ is an SPNET-LAsemihypergroup, hence

$$
\begin{aligned}
& a=s * a=a * s, s=t * a=a * t \\
& a=a * p=p * a, p=a * q=q * a
\end{aligned}
$$

we get

$$
\begin{gathered}
s * p=(t * a) * p=(p * a) * t=a * t=s \\
p * s=(q * a) * s=(s * a) * q=a * q=p \\
s * p=(a * t) *(q * a)=(a * q) *(t * a)=p * s
\end{gathered}
$$

Thus $p=s$, it implies s is unique and $s * s=s$.

(2) From (1), if $s=\operatorname{neut}(a) \in L$, then $s * s=s * s=s$, This implies neut $(s)=s$ and $s \in\{\}_{\text {anti }}(s)_{s}$.

(3) For any given $a \in L$, if $s=n e u t(a), t \in\{\}_{\text {anti }(a)_{s^{\prime}}}$, then

$$
a=a * s=s * a, s=a * t=t * a
$$

On the other hand, from neut(s) $=s$ and $r \in\{\}_{\text {anti(s) }}$, we get

$$
s=s * s=s * s, s=r * s=s * r
$$

Thus

$$
\bigcup_{m \in r * t}(m * a)=(r * t) * a=(a * t) * r=s * r=s
$$

where $m * a$ is a nonempty set, hence for any $m \in r * t, m * a=s$. This implies $m \in\{\}_{\text {lanti }(a)_{s}}$. In other words, $r * t \subseteq\{\}_{\text {lanti }(a)_{s}}$.

(4) By (2), (3), we can get (4).

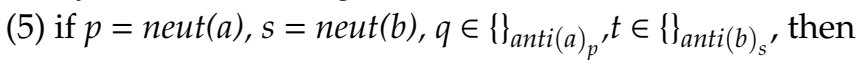

$$
\begin{aligned}
& (p * s) *(a * b)=(p * a) *(s * b)=a * b \\
& (a * b) *(p * s)=(a * p) *(b * s)=a * b .
\end{aligned}
$$

That is,

$$
(p * s) *(a * b)=(a * b) *(p * s)=a * b .
$$

On the other hand,

$$
\bigcup_{l \in q * t}[(a * b) * l]=(a * b) *(q * t)=(a * q) *(b * t)=p * s,
$$


where $(a * b) * 1$ is a nonempty set, $|a * b|=1$ and $|p * s|=1$. Hence for any $l \in q * t,(a * b) * 1=p * s$. In the same way, we can prove that for any $l \in q * t, l *(a * b)=p * s$. Thus for any $l \in q * t$,

$$
l *(a * b)=(a * b) * l=p * s .
$$

From (14), (15) and $|a * b|=|p * s|=1$, we get neut $(a * b)=p * s$ and $q * t \subseteq\{\}_{\text {anti }(a * b)_{p * s}}$.

(6) Let $p=s$ in Proposition 7 (5), we can get the conclusion.

(7) $(L, *)$ is an SPNET-LA-semihypergroup, hence for any given $a, b \in L$, there are neut $(a)=s, \operatorname{neut}(b)$ $=p, t \in\{\}_{\text {anti }(a)_{s}}, q \in\{\}_{\text {anti }(b)_{p}}$ such that

$$
\begin{gathered}
a=a * s=s * a, s=a * t=t * a \\
b=b * p=p * b, p=b * q=q * b .
\end{gathered}
$$

If $s=p$, then we have

$a * b=(a * s) *(b * p)=(a * b) *(s * p)=(a * b) *(s * s)=(a * b) * s=(s * b) * a=(p * b) * a=b * a$.

(8) Suppose that $b * a=c * a$ for $a, b, c \in L$. There are $s=$ neut $(a) \in L$ and $t \in\{\}_{\text {anti }(a)_{s}}$. Multiply $b * a=c *$ $a$ by $t$, we have

$$
\begin{aligned}
(b * a) * t & =(c * a) * t \\
(t * a) * b & =(t * a) * c \\
s * b & =s * c
\end{aligned}
$$

(9) For any given $a \in L$, there is $s=n e u t(a) \in L$, if $q, t \in\{\}_{\text {anti }(a) s_{s}}$, then

$$
s * q=(t * a) * q=(q * a) * t=s * t .
$$

Theorem 1. Suppose $(L, *)$ is a PRNET-LA-semihypergroup, for any $x \in L$,

(a) if $p \in\{\}_{\text {rneut }(x)}, q \in\{\}_{\text {ranti }(x)_{p}}$ and $|p * p|=1$, then

$$
p * \subseteq\{\}_{\text {lneut }(x)} \subseteq\{\}_{\text {lanti }(x)_{p * p}}
$$

and $(L, *)$ is an PLNET-LA-semihypergroup.

(b) if $p \in\{\}_{\text {rneut }(x)}, q \in\{\}_{\text {ranti }(x)_{p},}, p * p=p$ and $q \in p * q$, then

$$
p=\text { neutx } \in\{\}_{\text {anti }(x)_{p}}
$$

and $(L, *)$ is an SPNET-LA-semihypergroup.

Proof. (1) Since $(L, *)$ is a PRNET-LA-semihypergroup, for any given $x \in L$, there are $p \in\{\}_{\text {rneut }(x)}$ and $q$ $\in\{\}_{\text {ranti }(x)_{p}}$ such that

$$
x=x * p, p=x * q
$$

multiply $x=x * p$ by $p$, we have

$$
x=x * p=(x * p) * p=(p * p) * x
$$

In addition,

$$
\underset{s \in p * q}{\cup}(s * x)=(p * q) * x=(x * q) * p=p * p
$$


where $s * x$ is a nonempty set and $|p * p|=1$. Thus for any $s \in p * q, s * x=p * p$. It means that for any $x \in L$, there are $p * p, s \in p * q$ such that

$$
(p * p) * x=x, s * x=p * p
$$

It shows that

$$
p * p \subseteq\{\}_{\text {lneut }(x)}, s \in p * q \subseteq\{\}_{\text {lanti }(x)_{p * p}}
$$

By Definition $11,(L, *)$ is an LNET-LA-semihypergroup.

(2) By Theorem 1 (a),

$$
\begin{gathered}
p=p * p \in\{\}_{\text {lneut }(x)} \\
q \in p * q \subseteq\{\}_{\text {lanti }(x)_{p * p}}=\{\}_{\text {lanti }(x)_{p}}
\end{gathered}
$$

It shows that for any given $x \in L$, there is $p \in L$ such that

$$
p * x=x \text { and } q * x=p
$$

On the other hand, $p \in\{\}_{\text {rneut }(x)}, q \in\{\}_{\text {ranti }(x)_{p}}$, we get

$$
x=x * p \text { and } x * q=p
$$

Based on the above, for any given $x \in L$, there are $p$ and $q$ such that

$$
\begin{aligned}
& x=x * p=p * x \\
& p=x * q=q * x
\end{aligned}
$$

That is,

$$
p \in\{\}_{\text {neut }(x)} \text { and } q \in\{\}_{\text {anti }(x)_{p}}
$$

By Definition 11, $(L, *)$ is an SPNET-LA-semihypergroup. Applying Proposition 7 (1), we get $p=\operatorname{neut}(x)$.

Example 12. Put $L=\{0,1,2\}$, the binary hypergroupoid $(L, *)$ is as follows (see Table 11).

Table 11. The binary hypergroupoid $(L, *)$.

\begin{tabular}{cccc}
\hline$*$ & 0 & $\mathbf{1}$ & $\mathbf{2}$ \\
\hline 0 & 0 & 1 & $\{0,1,2\}$ \\
1 & 1 & 0 & $\{0,1,2\}$ \\
2 & $\{0,1,2\}$ & $\{0,1,2\}$ & 2 \\
\hline
\end{tabular}

By Python program, $(L, *)$ is an LA-semihypergroup. Furthermore, we have

$$
\begin{gathered}
\operatorname{rneut}(0)=0, \operatorname{rneut}(1)=0, \operatorname{rneut}(2)=2 \\
\operatorname{ranti}(0)_{\operatorname{rneut}(0)=0}, \operatorname{ranti}(1)_{\operatorname{rneut}(1)=0}, \operatorname{ranti}(2)_{\operatorname{rneut}(2)=2}=2 \\
0 * 0=0,0 * 0=0,2 * 2=2 \\
0 \in 0 * 0,1 \in 0 * 1,2 \in 2 * 2
\end{gathered}
$$

By Theorem $1(b)$, we know that $(L, *)$ is an SPNET-LA-semihypergroup.

Corollary 1. A PRNET-LA-semihypergroup $(L, *)$, which satisfies conditions of Theorem $1(b)$, then neut $(p * s)$ $=\operatorname{neut}(p) * \operatorname{neut}(s)$ if $|p * s|=|\operatorname{neut}(p) * \operatorname{neut}(s)|=1$, where $p, s \in L$. 
Proof. It follows from Theorem 1 (b) and Proposition 7 (5).

Corollary 2. An idempotent PRNET-LA-semihypergroup is a PLNET-LA-semihypergroup.

Proof. It follows from Theorem 1 (a).

Proposition 8. An idempotent PRNET-LA-semihypergroup with pure left identity is a commutative SPNET-LA-semihypergroup and its pure left identity is pure right identity.

Proof. Put e is a pure left identity of $(L, *)$. Then for any $t \in L$,

$$
e * t=t
$$

by idempotent law, we get

$$
t * e=(t * t) * e=(e * t) * t=t * t=t .
$$

It shows that $e$ is pure right identity of $(L *)$. Furthermore, for any $m, n \in L$,

$$
m * n=(m * e) * n=(n * e) * m=n * m
$$

It follows that $(L, *)$ satisfies commutative law.

On the other hand, $(L, *)$ is a PRNET-LA-semihypergroup. Hence for any given $a \in L$, there are $s \in\{\}_{\text {rneut }(a)}$ and $t \in\{\}_{\text {ranti }(a)_{s}}$ such that

$$
a=a * s, s=a * t
$$

Applying commutative law, we get

$$
a=a * s=s * a, s=a * t=t * a .
$$

Thus $(L, *)$ a commutative SPNET-LA-semihypergroup.

Proposition 9. Suppose $(L, *)$ is a PRNET-LA-semihypergroup (or a PLNET-LA-semihypergroup) with pure right identity, then pure right identity is pure left identity and $(L, *)$ is a commutative Net-semihypergroup.

Proof. Put $e$ is a pure right identity of $(L, *)$, Then for any given $t \in L$,

$$
t * e=t
$$

we have

$$
t=t * e=(t * e) * e=(e * e) * t=e * t .
$$

This shows that $e$ is pure left identity of $(L, *)$. Furthermore, for any $l, m, n \in L$,

$$
\begin{gathered}
m * n=(m * e) * n=(n * e) * m=n * m \\
(l * m) * n=(l * m) *(e * n)=(l * e) *(m * n)=l *(m * n) .
\end{gathered}
$$

It follows that $(L, *)$ satisfies commutative law and associative law. In addition, $(L, *)$ is a PRNET-LA-semihypergroup. Hence for any given $s \in L$, there are $p \in\{\}_{\text {rneut }(s)}$ and $q \in\{\}_{\text {ranti }(s)_{p}}$ such that

$$
s=s * p, p=s * q .
$$

Applying commutative law, we get

$$
s=s * p=p * s, p=s * q=q * s .
$$


By Definition $10,(L, *)$ is a commutative NET-semihypergroup.

Theorem 2. Let $(L, *)$ be a PRNET-LA-semihypergroup, which satisfies the following conditions:

(1) for any $t \in L$, there are $p \in\{\}_{\text {rneut }(t)}, q \in\{\}_{\text {ranti }(t)}$ such that

$$
p * p=p, q=p * q ;
$$

By condition (1), for a certain $q$ in (1), there are $r \in\{\}_{\text {rneut }(q)}, l \in\{\}_{\text {ranti }(q)_{r}}$ such that

$$
r * r=r, l=r * l
$$

(2) $|p * r|=1$, where $p$ in (16) and $r$ in (17);

(3) for any $m, n \in L$, if neut $(m)=\operatorname{neut}(n)$, then $|m * n|=1$.

Define an equivalent relation $\varphi$ on $L$,

$$
m \varphi n \text { if and only if neut }(m)=n e u t(n)
$$

Then

(a) (To every $t \in L,([t], *)$ is a sub NET-LA-semihypergroup of $(L, *)$, in which [t] is the equivalent class of $t$ based on equivalent relation $\varphi$;

(b) To every $t \in L,([t], *)$ is a regular LA-hypergroup.

Proof. (a) Firstly, by Theorem 1 (b) and Theorem 2's condition (1), we know that $(L, *)$ is an SPNET-LA-semihypergroup. Suppose $m, n \in[t]$, by Theorem 2's condition (3), we have

$$
\operatorname{neut}(m)=\operatorname{neut}(n)=\operatorname{neut}(t) \text { and }|m * n|=1
$$

Applying Proposition $7(6)$, we get neut $(m * n)=n e u t(t)$. It shows that $m * n \in[t]$.

Secondly, applying Proposition 7 (2), we have

$$
\operatorname{neut}(\operatorname{neut}(m))=\operatorname{neut}(\operatorname{neut}(t))=\operatorname{neut}(t)
$$

It means that for any $m \in[t], n e u t(m) \in[t]$.

Lastly, by Theorem 2's condition (1) and Theorem 1 (b), for any $m \in[t] \subseteq L$, there is $q \in L$ such that

$$
q=\operatorname{neut}(m) * q \in\{\}_{\text {anti }(m)_{\text {neut }(m)}}
$$

and for the $q$ in (18), there are $r \in\{\}_{\text {rneut }(q)}, l \in\{\}_{\text {ranti }(q)_{r}}$ such that

$$
\begin{aligned}
& r * r=r, l=r * l \\
& \text { and } r=\operatorname{neut}(q) .
\end{aligned}
$$

By Theorem 2's condition (2) and (19), we get

$$
|\operatorname{neut}(m) * r|=|\operatorname{neut}(m) * \operatorname{neut}(q)|=|\operatorname{neut}(\operatorname{neut}(m)) * \operatorname{neut}(q)|=1 \text {. }
$$

Applying Proposition 7 (5), we get

$$
\begin{gathered}
\operatorname{neut}(\operatorname{neut}(m) * q)=\operatorname{neut}(\operatorname{neut}(m)) * \operatorname{neut}(q)=\operatorname{neut}(m) * \operatorname{neut}(q) \\
=\operatorname{neut}(m * q)=\operatorname{neut}(\operatorname{neut}(m))=\operatorname{neut}(m)=\operatorname{neut}(t) .
\end{gathered}
$$

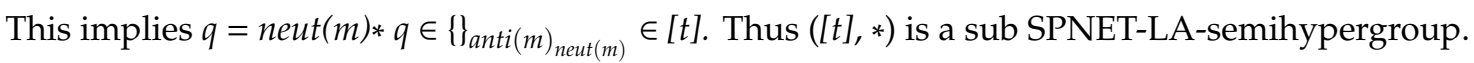


(b) Firstly, from (a), for any given $t \in L,([t], *)$ is a sub-SPNET-LA-semihypergroup of $(L, *)$. By the definition of $\phi$, if $m \in[t]$, then for any $n \in[t], n e u t(m)=n e u t(n)=n e u t(t)$. Applying Proposition 7 (7), we get

$$
m * n=n * m
$$

That is $m *[t]=[t] * m$.

Secondly, for any $s \in[t], s * m \in[t]$, hence $[t] * m \subseteq[t]$; On the other hand, by proof of (a), we know that for any $m \in[t]$, there is $q \in[t]$ such that

$$
q=\operatorname{neut}(m) * q\{\}_{\text {anti }(m)_{\text {neut }(m)}}
$$

hence for any $s \in[t], s * q \in[t]$. Thus

$$
s=\operatorname{neut}(s) * s=\operatorname{neut}(m) * s=(m * q) * s=(s * q) * m \subseteq[t] * m .
$$

That is, $[t] \subseteq[t] * m$. Thus $[t]=[t] * m=m *[t]$. It implies that $([t], *)$ is a LA-hypergroup.

Lastly, it can be easily proved that neut $(t)$ is a scalar identity of $([t], *)$ and for every $l \in[t]$ has at least one inverse. By Definition $8,([t], *)$ is a regular LA-hypergroup.

Corollary 3. If a PRNET-LA-semihypergroup ( $L, *)$ which satisfies conditions of Theorem 2 and $\phi$ is the equivalence relation on $L$ defined in Theorem 2 , then $L / \phi$ is the partition of set $L$.

Example 13. Put $L=\{0,1,2,3,4\}$, the binary hypergroupoid ( $L, *)$ is as follows (see Table 12).

Table 12. The binary hypergroupoid $(L, *)$.

\begin{tabular}{cccccc}
\hline$*$ & $\mathbf{0}$ & $\mathbf{1}$ & $\mathbf{2}$ & $\mathbf{3}$ & $\mathbf{4}$ \\
\hline 0 & 0 & 1 & $\{0,1,2\}$ & 0 & 4 \\
1 & 1 & 0 & $\{0,1,2\}$ & 1 & 4 \\
2 & $\{0,1,2\}$ & $\{0,1,2\}$ & 2 & $\{0,1,2\}$ & 4 \\
3 & 0 & 1 & $\{0,1,2\}$ & 3 & 4 \\
4 & 4 & 4 & 4 & 4 & 4 \\
\hline
\end{tabular}

By Python program, $(L, *)$ is LA-semihypergroup. Firstly, we have

$$
\begin{gathered}
\operatorname{rneut}(0)=0, \operatorname{rneut}(1)=0, \operatorname{rneut}(2)=2, \operatorname{rneut}(3)=3, \operatorname{rneut}(4)=4 \\
\operatorname{ranti}(0)_{\operatorname{rneut}(0)=0}=0, \operatorname{ranti}(1)_{\operatorname{rneut}(1)=0}=1, \operatorname{ranti}(2)_{\operatorname{rneut}(2)=2} 2, \operatorname{ranti}(3)_{\operatorname{rneut}(3)=3}, \operatorname{ranti}(4)_{\operatorname{rneut}(4)=4}=4 \\
0 * 0=0,0 * 0=0,2 * 2=2,3 * 3=3,4 * 4=4 \\
0=0 * 0,1=0 * 1,2=2 * 2,3=3 * 3,4=4 * 4 .
\end{gathered}
$$

These means that Theorem 2's condition 1) hold; Secondly, we get

$$
\begin{gathered}
\left|\operatorname{rneut} 0 * \operatorname{rneut}\left(\operatorname{ranti}(0)_{\operatorname{rneut}(0)=0}\right)\right|=|\operatorname{rneut}(0) * \operatorname{rneut}(0)|=|0|=1 \\
\left|() * \operatorname{rneut}\left(\operatorname{ranti}(1)_{\operatorname{rneut}(1)=0}\right)\right|=|\operatorname{rneut}(1) * \operatorname{rneut}(1)|=|0|=1 \\
\left|() * \operatorname{rneut}\left(\operatorname{ranti}(2)_{\operatorname{rneut}(2)=2}\right)\right|=|\operatorname{rneut}(2) * \operatorname{rneut}(2)|=|2|=1 \\
\left|() * \operatorname{rneut}\left(\operatorname{ranti}(3)_{\operatorname{rneut}(3)=3}\right)\right|=|\operatorname{rneut}(3) * \operatorname{rneut}(3)|=|3|=1 \\
\left|() * \operatorname{rneut}\left(\operatorname{ranti}(4)_{\operatorname{rneut}(4)=4}\right)\right|=|\operatorname{rneut}(4) * \operatorname{rneut}(4)|=|4|=1
\end{gathered}
$$


These means that Theorem 2's condition (2) hold. Lastly,

$$
\operatorname{rneut}(0)=\operatorname{rneut}(1)=0,|0 * 1|=1
$$

These means that Theorem 2's condition (3) hold. By Theorem 1 and Theorem 2, we know that $(L, *)$ is an SPNET-LA-semihypergroup and

$$
\begin{gathered}
L_{1}=\{0,1\}=[0]=[1], L_{2}=\{2\}=[2], L_{3}=\{3\}=[3], L_{4}=\{4\}=[4] \\
L=L_{1} \cup L_{2} \cup L_{3} \cup L_{4}
\end{gathered}
$$

where $\left(L_{1}, *\right),\left(L_{2}, *\right),\left(L_{3}, *\right),\left(L_{4}, *\right)$ are all regular $L A$-hypergroups.

Definition 14. An NET-LA-semihypergroup $(L, *)$ satisfies weak commutative law, if for any $y \in L$,

$$
p * y=y * p, q * x=x * q
$$

where $x$ is any element of set $L, p \in\{\}_{\text {neut }(x)}, q \in\{\}_{\text {anti }(x)_{p}}$.

Proposition 10. An SPNET-LA-semihypergroup $(L, *)$ satisfies weak commutative law if and only if it is a commutative.

Proof. If $(L, *)$ is a weak commutative, then for any $x, y \in L, l \in\{\}_{\text {neut }(x)}, m \in\{\}_{\text {neut }(y)}$, we have

$$
x * y=(x * l) *(y * m)=(l * x) *(y * m)=(l * y) *(x * m)=(y * l) *(m * x)=(y * m) *(l * x)=y * x
$$

That is, $(L, *)$ is commutative.

\section{Conclusions}

In this study, we give the new notions of NET-LA-semihypergroup, NET-LA-hypergroup, LNET-LA-semihypergroup, RNET-LA-semihypergroup, PLNET-LA-semihypergroup, PRNET-LAsemihypergroup, PNET-LA-semihypergroup, SPNET-LA-semihypergroup, discuss the relationships of them (see Figures 5 and 6), get some special properties of SPNET-LA-semihypergroup (see Proposition 7). In particular, we prove that a RNET-LA-semihypergroup which satisfies certain conditions(the condition of asymmetry) be an SPNET-LA-semihypergroup and this SPNET-LA-semihypergroup is the union of some disjoint regular hypergroups, where every regular hypergroup is its subhypergroup (see Theorem 2). At last, we discuss the relationships of various NET-LA-semihypergroups (see Figure 7).

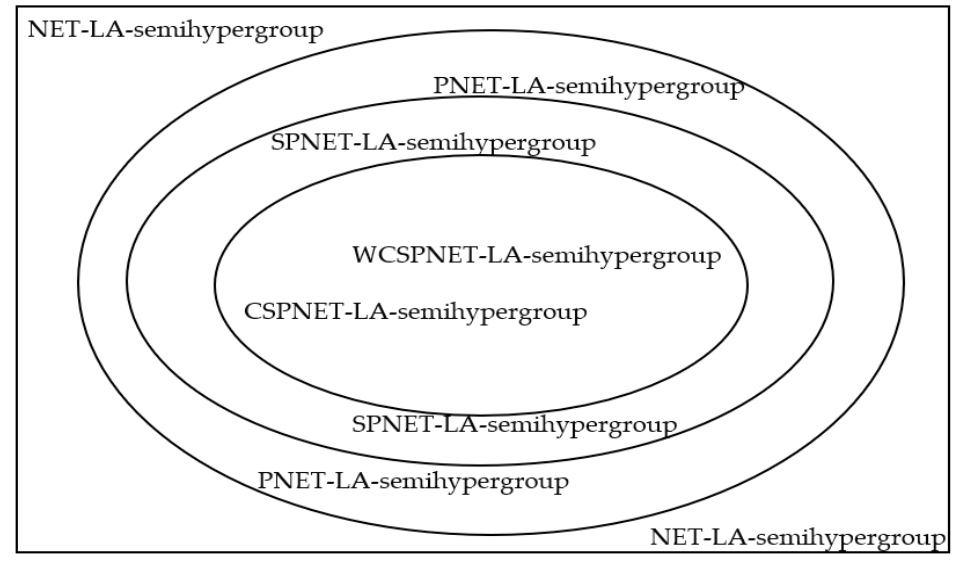

Figure 7. The relationships of various NET-LA-semihypergroups. 
These studies help us to enhence the understanding of this hyperalgebraic structure about NET and tell us this hyper algebraic structure is a complex and unique structure. There is still a lot of unknown knowledge in this field to explore. In the future, we will discuss properties of NET-CA-semihypergroup.

Author Contributions: F.S., X.Z. and M.H. proposed the idea of the research, M.H. wrote the paper. All authors have read and agreed to the published version of the manuscript.

Funding: This research was funded by National Natural Science Foundation of China (Grant No. 61976130).

Acknowledgments: I would like to express my gratitude to Florentin Smarandache and Xiaohong Zhang, for their intructive advice and useful suggestions on this paper.

Conflicts of Interest: The authors declare no conflict of interest.

\section{References}

1. Kazim, M.A.; Naseeruddin, N. On almost semigroups. Aligarh Bull. Math. 1972, 2, 1-7.

2. Marty, F. Sur Une Generalization de la Notion de Groupe. In Proceedings of the 8th Congres des Mathematicians Scandinaves, Stockholm, Sweden, 14-18 August 1934; pp. 45-49.

3. Vougiouklis, T. Hyperstructures and Their Representations; Hadronic Press: Palm Harbor, FL, USA, 1994.

4. Howie, J.M. Fundamentals of Semigroup Theory; Oxford University Press: Oxford, UK, 1995.

5. Corsini, P.; Leoreanu, V. Applications of Hyperstructure Theory; Springer: Berlin/Heidelberg, Germany, 2003.

6. Davvaz, B. Semihypergroup Theory; Elsevier: Amsterdam, The Netherlands, 2016.

7. Hila, K.; Dine, J. On hyperideals in left almost semihypergroups. ISRN Algebra 2011, 2011, 953124. [CrossRef]

8. Yaqoob, N.; Corsini, P.; Yousafzai, F. On intra-regular left almost semihypergroups with pure left identity. J. Math. 2013, 2013, 510790. [CrossRef]

9. Amjad, V.; Hila, K.; Yousafzai, F. Generalized hyperideals in locally associative left almost semihypergroups. N. Y. J. Math. 2014, 20, 1063-1076.

10. Yaqoob, N.; Gulistan, M. Partially ordered left almost semihypergroups. J. Egypt. Math. Soc. 2015, 23, 231-235. [CrossRef]

11. Yousafzai, F.; Hila, K.; Corsini, P.; Zeb, A. Existence of non-associative algebraic hyperstructures and related problems. Afr. Mat. 2015, 26, 981-995. [CrossRef]

12. Rehman, I.; Yaqoob, N.; Nawaz, S. Hyperideals and hypersystems in LA-hyperrings. Songklanakarin J. Sci. Technol. 2017, 39, 651-657.

13. Nawaz, S.; Rehman, I.; Gulistan, M. On left almost semihyperrings. Int. J. Anal. Appl. 2018, 16, 528-541.

14. Smarandache, F.; Ali, M. Neutrosophic triplet group. Neural Comput. Appl. 2018, 29, 595-601. [CrossRef]

15. Gulistan, M.; Nawaz, S.; Hassan, N. Neutrosophic Triplet Non-Associative Semihypergroups with Application. Symmetry 2018, 10, 613. [CrossRef]

16. Smarandache, F. Neutrosophic Perspectives: Triplets, Duplets, Multisets, Hybrid Operators, Modal Logic, Hedge Algebras. And Applications; Pons Publishing House: Brussels, Belgium, 2017.

17. Zhang, X.H.; Hu, Q.Q.; Smarandache, F.; An, X.G. On neutrosophic triplet groups: Basic properties, NT-subgroups, and some notes. Symmetry 2018, 10, 289. [CrossRef]

18. Jaíyéolá, T.G.; Smarandache, F. Some sesults on neutrosophic triplet group and their applications. Symmetry 2018, 10, 202. [CrossRef]

19. Zhang, X.H.; Wu, X.Y.; Mao, X.Y.; Smarandache, F.; Park, C. On neutrosophic extended triplet groups (Loops) and Abel-Grassmann's Groupoids (AG-Groupoids). J. Intell. Fuzzy Syst. 2019, 37, 5743-5753. [CrossRef]

20. Wu, X.Y.; Zhang, X.H. The decomposition theorems of AG-neutrosophic extended triplet loops and strong AG-(l,l)-loops. Mathematics 2019, 7, 268. [CrossRef]

21. Ma, Y.C.; Zhang, X.H.; Yang, X.F.; Zhou, X. Generalized neutrosophic extended triplet group. Symmetry 2019, 11, 327. [CrossRef]

22. Zhang, X.H.; Wang, X.J.; Smarandache, F.; Jaíyéolá, T.G.; Lian, T.Y. Singular neutrosophic extended triplet groups and generalized groups. Cogn. Syst. Res. 2019, 57, 32-40. [CrossRef]

23. Zhang, X.H.; Samarandache, F.; Ma, Y.C. Neutrosophic Extended Triplet Semihypergroups and Regular Hypergroups. Symmetry 2019, 11, 1217. [CrossRef]

24. Zhang, X.H.; Mao, X.Y.; Wu, Y.T.; Zhai, X.H. Neutrosophic filters in pseudo-BCI algebras. Int. J. Uncertain. Quan. 2018, 8, 511-526. [CrossRef] 
25. Zhang, X.H.; Borzooei, R.A.; Jun, Y.B. Q-filters of quantum B-algebras and basic implication algebras. Symmetry 2018, 10, 573. [CrossRef]

26. An, X.G.; Zhang, X.H.; Ma, Y.C. Generalized Abel-Grassmann's Neutrosophic Extended Triplet Loop. Mathematics 2019, 7, 1206. [CrossRef]

(c)

(C) 2020 by the authors. Licensee MDPI, Basel, Switzerland. This article is an open access article distributed under the terms and conditions of the Creative Commons Attribution (CC BY) license (http://creativecommons.org/licenses/by/4.0/). 